\title{
Organic acids analysis in "Brandy de Jerez" by ion-exclusion chromatography, "post-column" buffering and conductimetric detection*
}

\author{
D.A. Guillén ${ }^{1}$, C.G. Barroso ${ }^{1}$, L. Zorro ${ }^{1}$, V. Carrascal ${ }^{2}$ and J.A. Pérez-Bustamante ${ }^{1}$ \\ ${ }^{1}$ Department of Analytical Chemistry, Faculty of Sciences, University of Cádiz, \\ P.O. Box 40, E-11510-Puerto Real (Cádiz), Spain \\ ${ }^{2}$ Consejo Regulador de la Denominación Específica “Brandy de Jerez”, Cervantes 3, \\ E-11403-Jerez,(Cádiz), Spain
}

\begin{abstract}
A rapid ion-exclusion chromatographic method with conductimetric detection for the determination of the main carboxylic acids (citric, tartaric, malic, fumaric, succinic, lactic, formic and acetic acids) in "Brandy de Jerez" is described. In order to increase the detection sensitivity, a pH 6.5 buffer is added to the column effluent to ensure that the analytes are ionized. The linearity, sensitivity and repeatibility were evaluated for each acid. Detection limits ranging from $43.054 \mathrm{mg} / \mathrm{L}$ (acetic acid) to $0.732 \mathrm{mg} / \mathrm{L}$ (succinic acid) were obtained. The ion exclusion with "post-column" buffering and conductimetric detection permits the analysis of brandies without interferences from sugars and phenolic compounds.
\end{abstract}

Key words. Organic acids - Brandy — ion-exclusion chromatography — conductimetric detection.

\section{Introduction}

"Brandy de Jerez" is matured by means of the traditional «soleras» system. This involves using oak casks that have previously been used for the maturing and ageing of sherry wine, during which the interior surface of the cask absorbs components of the sherry, in particular tartaric and other short-chain organic acids. Some of these components are subsequently taken up by the brandy, giving it a characteristic profile containing traces of these organic acids. This profile can be used as a criterion to determine the origin and length of ageing of the brandy.

The characterisation of Brandy de Jerez has become extremely interesting for two important reasons. The first concerns the possibility of differentiating the product 
analytically from all the other similar products on the market, thus protecting its authenticity. And a second reason, aiming at achieving the highest possible product quality in Brandy de Jerez, is that a useful way of analytically monitoring the brandy during its maturation process may be devised. It is during this process that variables such as humidity and temperature in the cellar, oxygenation and exposure to light, the characteristics of the oak casks, alcoholic content of the spirit and so on, exert their influence in various ways on the product's final composition.

Many papers have been published on acid determination in foods and beverages [1-3]. In wine, the analysis of organic acids is commonly carried out by reversed phase chromatography [4-7], ion-exchange chromatography [8], or ion exclusion chromatography [9], normally using refractive index or UV detection. The former detection system is characterised by its low sensitivity and so is generally only suitable for detecting the major compounds; while UV detection is very sensitive to many interferent compounds, which makes it necessary to employ inconvenient preparatory stages for sample preparation [10,11]. The levels of organic acids are relatively low and there are a significant number of interferent species such as phenolic compounds in "Brandy de Jerez". Given this situation, it may be useful to have an alternative means of detection with a greater degree of selectivity and sensitivity. Ion-exclusion chromatography with conductimetric detection has poor sensitivity for the detection of sugars and also, there is little interference with carboxylic acid determination [12,13]. However, it is difficult to apply this method since the necessary use of a mobile phase in ion-exclusion chromatography leads to a decreased response to the organic acids due to the inhibition of their dissociation. A way around the problem involves dissociation of the organic acids by buffering the effluent from the column [14].

In the present work, a suitable method for the analysis of organic acids in Brandy de Jerez has been optimized. It is based on chromatographic separation through an ion-exclusion column, using a dilute solution of trifluoracetic acid as the mobile phase, followed by conductimetric detection. In order to increase the sensitivity prior to the detection, a buffer of $\mathrm{pH} 6.5$ is added to the mobile phase to ensure the ionization of the analytes.

\section{Experimental}

\section{Reagents}

All chemical species used, of analytical reactive quality, were obtained from Merck (Darmstadt, Germany). The water used was purified in a Milli-Q system (Millipore, Bedford, MA, USA). All the solvents used as elution phases, and all the samples, were filtered through $0.45 \mu \mathrm{m}$ membranes.

\section{Apparatus}

The instrument arrangement comprised: two Model 2150 pumps and a Model 2155 oven for the columns, all from LKB (Pharmacia, Sweden); a Model Conductomonitor III, conductivity detector from Milton Roy (LDC, Florida, USA); a Model 717 automatic injector and a Millenium data treatment system, both from Waters (Milford, MA, USA).

\section{Chromatographic conditions}

The chromatographic separation was carried out with two ION-300, Ion-exclusion columns (Interaction Chromatography, S. José, CA, USA) installed in series $(300 \mathrm{~mm}$ length, $4.6 \mathrm{~mm}$ ID). The oven temperature was set at a constant $\left(60^{\circ} \mathrm{C}\right)$. The mobile phase used was a $2.5 \mathrm{mM}$ solution of trifluoroacetic acid (TFA) with a flow rate of $0.4 \mathrm{~mL} / \mathrm{min}$. The sample volume injected was $20 \mu \mathrm{L}$. In order to increase the detection sensitivity, a solution consisting of $2.5 \mathrm{mM}$ of TFA, $20 \mathrm{mM}$ of bis-tris buffer and $100 \mathrm{mM}$ of EDTA was added at the outlet of the column, by means of the second pump, at a flow rate of $0.4 \mathrm{~mL} / \mathrm{min}$.

\section{Samples}

For the final preparation of the chromatographic elution and the subsequent construction of the corresponding calibration curves, model solutions were used; these were composed of a $35 \%(\mathrm{v} / \mathrm{v})$ ethanol in water medium in which citric, tartaric, malic, fumaric, succinic, lactic, formic and acetic acid, in concentrations ranging between 5.8 and $806 \mathrm{mg} / \mathrm{L}$, were dissolved.

The samples of "Brandy de Jerez" analyzed, all of which were from commercial products, were supplied by the Regulatory Commission for the Specific Denomination of "Brandy de Jerez".

In all cases, the samples were filtered through $0.45 \mu \mathrm{m}$ membranes before injection.

\section{Results and discussion}

When the conductimetric detection method is used to detect ionizable species, it is influenced by the $\mathrm{pH}$ of the mobile phase in which they are eluted. In the present study which takes as its starting point the experimental conditions described by Hayashy [14], the variables (composition of the mobile phase, temperature at which the chromatographic separation is performed, and composition of the post-buffering phase) were optimized in order to determine the organic acids present in Brandy de Jerez.

Firstly, the composition of the mobile phase was optimized, which enabled the best resolution of the peaks corresponding to the eight organic acids present in the Brandy de Jerez by trials with p-toluenesulfonic acid, trifluoroacetic acid, sulfuric acid and phosphoric acid. The best option proved to be trifluoroacetic acid (TFA) at a concentration of $2.5 \mathrm{mM}$; this produced a good resolution and an acceptable background in the detector.

With regard to the temperature at which the chromatographic separation was performed, it was determined that the optimum corresponded to $60{ }^{\circ} \mathrm{C}$.

For the post-buffering stage, the same phase as before (TFA $2.5 \mathrm{mM}$ ) was added by means of a T connector at the outlet of the column. In addition, a buffer of low conductivity, bis-[2-hydroxyethyl]-iminotris-[hydroxymethyl]methane, (BIS-TRIS), was incorporated. This was proved to present an adequate buffering capacity, since the $\mathrm{pH}$ of the effluent at the system outlet was 6.5. Also EDTA at a concentration of $100 \mu \mathrm{M}$ was added to this phase, to prevent the formation of coordination complexes between the citric acid and the possible metallic traces present. And to prevent 
Table I. Effect of post-column buffering on the sensitivity of the method.

\begin{tabular}{|c|c|c|c|c|c|c|c|}
\hline \multirow[b]{2}{*}{ Compound } & \multirow[b]{2}{*}{$\begin{array}{c}t_{R} \\
(\mathrm{~min})\end{array}$} & \multirow[b]{2}{*}{$\begin{array}{l}R S D \\
(\%)\end{array}$} & \multicolumn{2}{|c|}{$\begin{array}{l}\text { Without } \\
\text { buffering }\end{array}$} & \multicolumn{2}{|c|}{$\begin{array}{c}\text { With } \\
\text { buffering }\end{array}$} & \multirow[b]{2}{*}{$B / A$} \\
\hline & & & $\begin{array}{c}\text { Area } \\
(\mu V s) \\
(A)\end{array}$ & $\begin{array}{l}R S D \\
(\%)\end{array}$ & $\begin{array}{c}\text { Area } \\
(\mu V s) \\
(B)\end{array}$ & $\begin{array}{c}R S D \\
(\%)\end{array}$ & \\
\hline Citric Acid & 19.77 & 0.08 & 6787 & 0.68 & 14158 & 1.88 & 2.09 \\
\hline Tartaric Acid & 20.95 & 0.05 & 7772 & 0.63 & 10048 & 3.22 & 1.29 \\
\hline Malic Acid & 24.74 & 0.05 & 3170 & 1.03 & 8124 & 3.15 & 2.56 \\
\hline Succinic Acid & 31.68 & 0.07 & 1093 & 6.70 & 9037 & 3.23 & 8.27 \\
\hline Fumaric. Acid & 32.85 & 0.02 & 6871 & 2.09 & 8489 & 0.58 & 1.23 \\
\hline Lactic Acid & 34.11 & 0.03 & 790 & 8.83 & 3138 & 5.69 & 3.97 \\
\hline Formic Acid & 36.29 & 0.07 & 1320 & 8.52 & 3839 & 9.22 & 2.90 \\
\hline Acetic Acid & 40.67 & 0.07 & 172 & 30.47 & 2645 & 13.65 & 15.37 \\
\hline
\end{tabular}

Table IIa. Characteristics of the calibration curves.

\begin{tabular}{lcccc}
\hline Compound & $\begin{array}{c}\text { Explored Range Regression } \\
(\mathrm{mg} / \mathrm{L})\end{array}$ & $\begin{array}{c}\text { Slope } \\
\text { coefficient }\end{array}(\mu \mathrm{Vs} \mathrm{L} / \mathrm{mg})$ & $\begin{array}{c}\text { Intercept } \\
(\mu V s)\end{array}$ \\
\hline Citric Acid & $10.60-213.20$ & 0.9991 & 126.7506 & -384.1767 \\
Tartaric Acid & $15.04-300.80$ & 0.9997 & 122.6523 & -977.3872 \\
Malic Acid & $13.36-336.72$ & 0.9978 & 148.8978 & -2148.4302 \\
Fumaric Acid & $5.80-115.52$ & 0.9994 & 246.8204 & -335.4398 \\
Lactic Acid & $11.60-388.99$ & 0.9999 & 55.6390 & -348.8357 \\
Succinic Acid11.76-130.88 & 1.0000 & 208.4457 & -320.7854 \\
Formic Acid & $9.88-98.80$ & 0.9999 & 194.8948 & -363.9608 \\
Acetic Acid & $6.01-806.61$ & 0.9989 & $127.9628-2041.3522$
\end{tabular}

Table IIb. Performance characteristics of the analytical method.

\begin{tabular}{lccccc}
\hline Compound & $\begin{array}{c}\text { Analytical DetectionQuantitation } \\
\text { Sensitivity }\end{array}$ & $\begin{array}{c}\text { Limearity Recovery } \\
\text { Limit }\end{array}$ & $\begin{array}{c}\text { Limit } \\
(\text { LOQ },\end{array}$ & & \\
& & LOL \% $)$ & $(\%)$ \\
$m g / L)$ & & \\
\hline Citric Acid & 3.3288 & 9.415 & 31.384 & 98.460 & 96.21 \\
Tartaric Acid & 4.1642 & 10.819 & 36.063 & 98.638 & 112.10 \\
Malic Acid & 6.2998 & 16.367 & 54.558 & 96.168 & 86.96 \\
Fumaric Acid & 1.7411 & 4.523 & 15.078 & 98.016 & 88.58 \\
Lactic Acid & 2.9252 & 7.600 & 25.333 & 99.052 & 100.43 \\
Succinic Acid & 0.2817 & 0.732 & 2.440 & 99.708 & 99.22 \\
Formic Acid & 0.4087 & 1.062 & 3.539 & 99.408 & 96.43 \\
Acetic Acid & 16.0454 & 43.054 & 143.514 & 97.705 & 103.06 \\
\hline
\end{tabular}

the pulse produced by the second pump from affecting the detection, a restrictor was inserted between the pump and the $T$ connector to dampen this pulse.

Table I shows the results obtained from the study of the influence of the post-column buffering. The peak areas for standard solutions of carboxylic acids obtained by direct electric conductivity detection were compared with those obtained with post-buffering prior to detection. As can be seen, this technique enabled the signal to be multiplied significantly, by a factor of 15.37 in case of acetic acid, without producing any significant changes in the repeatability of the method. In direct detection, sensitivity is influenced by
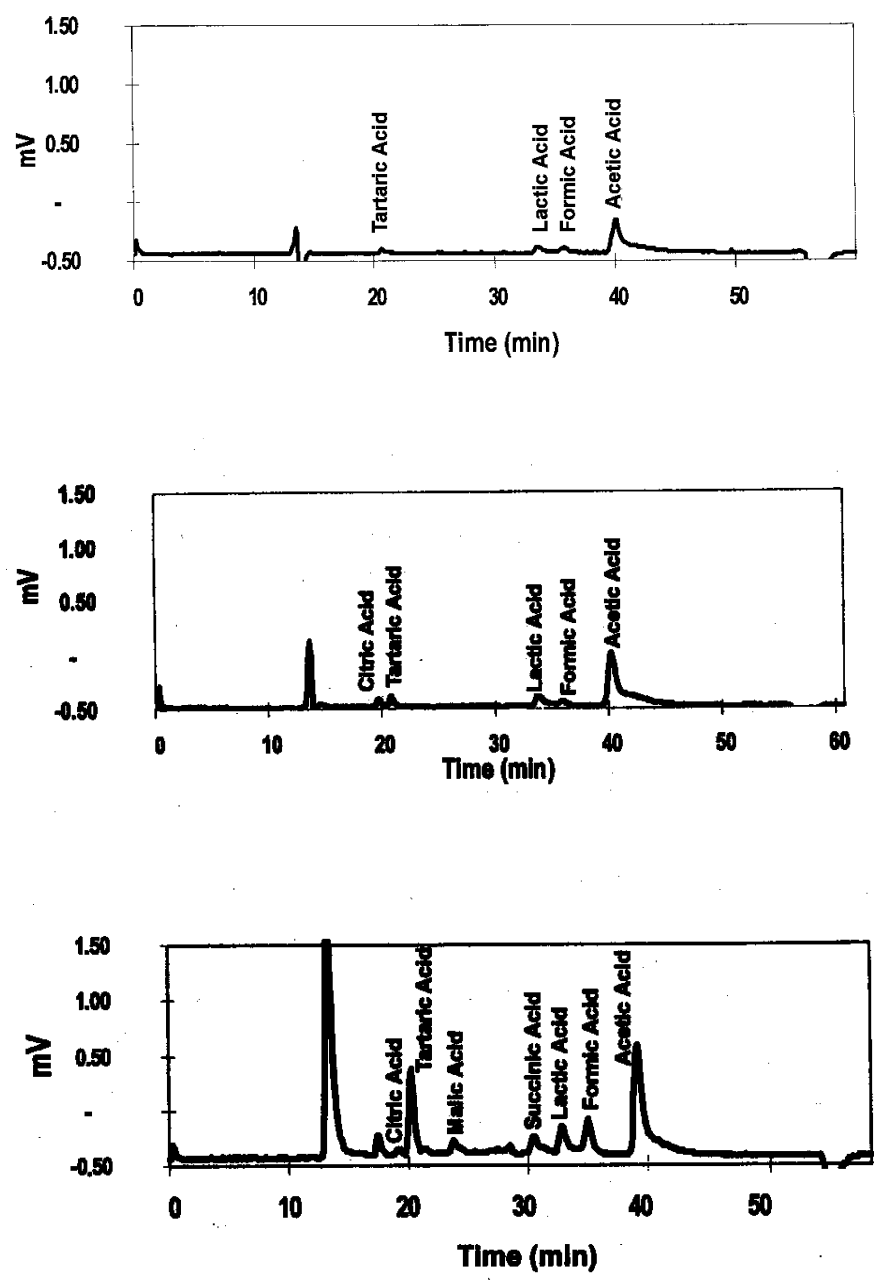

Fig. 1. Profile of the organic acids content of the three classes of Brandy de Jerez. A) Brandy "Solera", B) Brandy "Solera Reserva", C) Brandy "Solera Gran Reserva".

the concentration of the mobile phase acid while in postbuffering method, sensitivity can be kept almost constant by adjusting the concentration of the buffer solution according to the acidity of the mobile phase.

In order to validate this method, a series of calibration curves were constructed using the organic acids anticipated to be present in Brandy de Jerez; the calibration ranges were based on the expected concentrations of these acids. Repeatability of both retention times and peak areas was studied on the basis of 12 injections, and the values obtained are shown in table IIa.

Another series of parameters related to the performance of the analytical method was calculated from the calibration curves previously constructed using the ALAMIN computer program [15].

As can be seen, the method appears linear for the ranges of concentrations and the acids studied; and the limits of detection achieved are lower than those obtained using the refractive index detection system.

In order to check the accuracy of the method, the technique of standard additions was used. A sample of representative commercial brandy was taken as the matrix sample. Then known quantities of analytes were added at 5 
levels and in triplicate. The slopes of the lines thus obtained for each of the acids by this method were compared with the corresponding slopes obtained in the calibration with standards, using the $t$ criterion. No significant differences were found between them.

Table IIb gives the data for the recovery of the analytes added, determined by the slope of the line plotting the concentration found against the concentration expected.

The method developed was applied to various samples of brandy from the Specific Denomination of "Brandy de Jerez". Figure 1 shows the chromatograms obtained for three representative samples of each of the classes of Brandy de Jerez. As can be seen from these chromatograms, the conductimetric detection method is demonstrated to be very selective, and with a good detection limit, allowing an acceptable integration for the determination of organic acids, with no significant interferences being observed.

It is considered that the analysis of the organic acids content of "Brandy de Jerez" by this method would be an appropriate criterion for the characterization of the different classes of this product.

\section{Acknowledgments}

This study was carried out as part of the Collaboration Agreement between the Consejo Regulador de la Denominacion Especifica "Brandy de Jerez" and the University of Cádiz.

\section{References}

1. Bevilacqua, A. E.; Califano, A. N. J. Food Sci. 1989, 54(4), 1076.

2. Lopez, M. J.; Simal, J.; Romero, M. A. Anal. Bromatol. 1989, 41(1), 65.

3. Romero, M. A.; Gonzalez, M. V.; Lage-Yusty, J.; Lopez, M. J.; Pasbiro, P.; Simal, J. Anal. Bromatol. 1990, 42(2), 299.

4. Olalla, M.; López, H.; Villalón, M.; López, C. J. Liq. Chromatogr. 1993, 16(4), 3101.

5. Tusseau, D.; Benoit, C. J. Chromatogr. 1987, 395, 323.

6. Goiffon, J. P.; Blachere, A.; Reminiac, C. Analusis 1985, 13, 218.

7. García, E.; Sánchez, G.; Martín, P. J.; Cabezudo, M. D. J. Chromatogr. A. 1993, 655, 111.

8. Mongay, C.; Pastor, A.; Olmos, C. J. Chromatogr. A. 1996, 736, 351 .

9. Pfeiffer, P.; Radler, F. Z. Lebensm.-Unters.-Forsch. 1985, 181, 24.

10. Andersson, R.; Hedlund, B. Z. Lebensm.-Unters.-Forsch. 1983, 176,440 .

11. Calull, M.; Marcé, R. M.; Borrull, F. J. Chromatogr. A. 1992, 590,215

12. Tanaka, K.; Fritz, J. S. J. Chromatogr. 1987, 409, 271.

13. Lee, D. P.; Lord, A. D. $L C-G C$ 1987, 5, 261.

14. Hayashi, M. GIT-Spezial-Chromatogr. 1995,1, 64.

15. García, A. M.; Cuadros, L.; Alés, F.; Román, M. Trends Anal. Chem. 1997, 16(7), 381. 